\title{
Effectiveness of Mindfulness-based Stress Reduction on Hypertension among Patients with Metabolic Syndrome
}

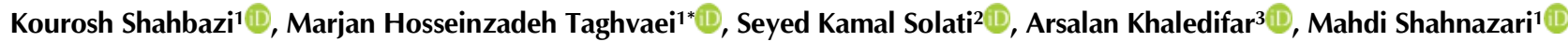 \\ 1. Department of Psychology, Karaj Branch, Islamic Azad University, Karaj, Iran \\ 2. Department of Psychology, Faculty of Medicine, Shahrekord University of Medical Sciences, Shahrekord, Iran \\ 3. Department of Cardiology, Faculty of Medicine, Shahrekord University of Medical Sciences, Shahrekord, Iran
}

*Corresponding author: Marjan Hosseinzadeh Taghvaei Department of Psychology, Karaj Branch, Islamic Azad University, Karaj, Iran

Email: msjantaghvai@gmail.com

Received: 27 Sep. 2020 Accepted: 05 Mar. 2021 ePublished: 01 Nov. 202

\begin{abstract}
Background and Objective: Marital Reducing stressors is an effective way to decrease blood pressure and its other associated symptoms. The present study aimed to investigate the effectiveness of mindfulness-based stress reduction (MBSR) on metabolic syndrome among patients with hypertension.

Materials and Methods: This experimental research was conducted based on a pretest-posttest control group design. A total number of 50 cardiovascular patients referring to Shahrekord Cohort Study, Shahrekord, Iran, in 2019 were selected using the convenience sampling method and randomly divided into experimental and control groups $(n=25$ each). Metabolic syndrome indices, including blood pressure, blood sugar, glucose triglyceride, high-density lipoprotein, and low-density lipoprotein, were used to collect the required data. All groups received the same standard medications under the supervision of an interventional cardiologist. In addition to the standard medical treatment, the experimental group received the intervention of MBSR (eight 90-minute sessions). The control group did not receive any non-pharmacological intervention. Data were analyzed using multivariate analysis of covariance.

Results: The results showed that MBSR was effective in improving metabolic syndrome symptoms in cardiovascular patients with hypertension $(\mathrm{P}<0.05)$.

Conclusions: The employment of MBSR along with medical and pharmacological treatments could help cardiovascular disease patients to improve the symptoms of metabolic syndrome.
\end{abstract}

Keywords: Cognitive, Heart disease, Metabolic syndrome, Mindfulness-based stress reduction, Stress and social isolation, affect the disease course, and therefore, are important both as main and primary risk factors affecting the onset of the disease [6]. Despite all the mentioned facts, few studies have been conducted concerning the effects of stress reduction interventions, including mindfulness [7, 8]. Mindfulness is a concept rooted in the Buddhist tradition which represents awareness of all external and internal experiences at the moment [9]. According to Jon Kabat-Zinn, mindfulness is a kind of consciousness through paying attention in a certain way and in the present moment, and without having any judgment on the experiences of the moment [10]. Mindfulness encourages the person to observe all emotions through a detached point of view. Mindfulness has been practiced in Buddhism for centuries and used in therapeutic interventions for common psychological problems, such as stress, worry, anxiety, and depression, since the 1970s [11]. Mindfulness-based stress reduction (MBSR) therapy focuses on avoiding judgment, raising 
consciousness, and focusing on the present moment. Through these three factors, it helps individuals process their cognitive, physiological, and behavioral activities [12]. The results of various pieces of research have indicated the effectiveness of this therapy on increasing the quality of life of cardiovascular patients, type two diabetes patients, patients with chronic low back pain, patients with multiple sclerosis, and women suffering from obesity [13-17].

Mindfulness is an active cognitive construct that is able to completely moderate the response of individuals to stressful and emotional situations. In this way, mindfulness, using conscious attention and flexible attention, causes the person to distance himself from emotional and habitual reactions and plan an appropriate response rather than reacting to the situation. Therefore, recognizing the effects of this type of intervention, especially mindfulness training based on stress reduction on psychological symptoms, is essential for mental health professionals [14]. The results of the studies have demonstrated that all diseases, especially cardiovascular disease and hypertension, have psychosomatic origins and are influenced by stress and stressful events. Accordingly, reducing stressors is an effective way to decrease blood pressure and its other associated symptoms [18]. Although having stress is inevitable and having enough stress promotes growth and development, high levels of stress or ineffective coping strategies are detrimental.

During MBSR therapy, people learn to develop acceptance and compassion instead of judging their experiences. They also learn to create presentmoment awareness rather than spontaneous thinking and apply new ways of responding to situations. Based on the results of a study conducted by Zare et al. [19], MBSR had an effective role in reducing the symptoms of diabetes. In another research, Mohammadi Shirmahaleh et al. [20] showed that mindfulness training significantly reduced anxiety and blood sugar level in patients with diabetes.

According to the findings of a study performed by Daubenmier et al. [21], mindfulness intervention may lead to long- term maintenance of fasting glucose levels and improved atherogenic lipid profiles. The results of a study carried out by Guyot et al. [22] were indicative of the existence of an association of higher mindfulness with lower odds of developing a metabolic syndrome, a lower waist circumference, higher high-density lipoprotein (HDL)-cholesterol, and lower level of fasting blood glucose among individuals with depressive symptomatology. Based on the findings of a study performed by Monin et al. [23], engagement in MBSR as a couple to address symptoms of metabolic syndrome was well-received and feasible, and preliminary effects suggested more benefits for wives than husbands in terms of physical functioning and relational well-being.

The innovation of the present study was to evaluate the effectiveness of MBSR and cognitive therapy on hypertension in patients with metabolic syndrome.

\section{Objectives}

According to the mentioned cases, due to the prevalence of symptoms of metabolic syndrome among patients with hypertension, and the importance of such interventions along with drug interventions, the present study aimed to investigate the effectiveness of MBSR on the metabolic syndrome components in cardiovascular patients with hypertension.

\section{Materials and Methods}

This experimental research was conducted based on a pretest-posttest control group design. The statistical population included all cardiovascular patients referring to Shahrekord Cohort Study, Shahrekord, Iran, in 2019, who were clinically examined by a cardiologist. The samples $(n=50)$ were selected using the convenience sampling method and randomly divided into experimental and control groups ( $\mathrm{n}=25$ each). The inclusion criteria were being diagnosed with hypertension and symptoms of metabolic syndrome by a cardiologist, being in the age range of 25-65 years, having secondary education, having the ability to participate in training sessions, providing informed consent to participate in the research. On the other hand, the patients who had psychiatric disorders and took medication, simultaneously participated in another psychological and therapeutic program, and were absent in more than two treatment sessions were excluded from the study.

Before the intervention, all the medical test samples related to metabolic syndrome and the blood pressure of patients were taken. After the intervention, laboratory monitoring was executed and blood pressure was taken again. In this regard, blood pressure levels higher than $140.90 \mathrm{~mm} \mathrm{Hg}$ and $150.80 \mathrm{~mm} \mathrm{Hg}$ were considered hypertensive for individuals under and over 60 years old, respectively [24].

Moreover, to apply the maximum control, a cardiologist provided a checklist that included the factors that might affect the process of taking blood pressure. Moreover, the physician considered the clinical examination while checking 
the blood pressure. After selecting the eligible samples and randomly assigning them to the experimental and control groups, all groups received the same standard medications under the supervision of an interventional cardiologist. In addition to the standard medical treatment, the experimental group received MBSR intervention (eight 90-minute sessions); however, the control group did not receive any non-pharmacological intervention. After the last training session, test samples of metabolic syndrome and blood pressure levels of patients in both groups were gathered again under the same conditions. Regarding the ethical considerations, the participants were informed of the right to leave the study at any time. Moreover, all participants were assured of confidentiality in this study. Moreover, the participants' rights were observed in this study.

\section{Research instruments}

Measuring the blood pressure and metabolic syndrome: systolic and diastolic blood pressure were measured and recorded by an interventional cardiologist using a standard sphygmomanometer in patients. Metabolic syndrome parameters, including fasting blood glucose (sugar) level, triglyceride, HDL, and low-density lipoprotein were measured. These parameters were measured through testing the blood sample of patients (after $10-12 \mathrm{~h}$ of fasting) by the medical laboratory during 8-9 am and after the prescription of the interventional cardiologist. The test results were observed and interpreted by the interventional cardiologist.

\section{Intervention program}

The intervention program consisted of eight 90minute sessions of MBSR intervention [25]. Table 1 presents the summary of the sessions.
Statistical analyses

After collecting data in the present study, in descriptive statistics, mean, standard deviation, minimum, and maximum scores were used. Inferential statistics section: Analysis of covariance (ANCOVA) was utilized to analyze the data. To investigate the assumptions of the inferential test, Leven's test (to investigate the equality of variances) and Shapiro-Wilk test (to examine the distribution normality of pre-test and post-test scores) were used. The results showed that the distribution of data was normal. The above statistical analysis was performed using SPSS.24 software.

\section{Results}

The participants included 50 cardiovascular patients with hypertension, aged between 25 and 65 years old. In the experimental group, $48 \%$ and $52 \%$ of the participants were female and male with the mean age of 38.52 and 42.38 years, respectively. In the control group, $40 \%$ and $60 \%$ of the participants were female and male with the mean age of 42.31 and 40.20 years, respectively. Table 2 presents the mean and standard deviation (SD) of the pre-test and post-test scores of components of metabolic syndrome for the experimental and control groups. The data were tested by the ANCOVA to investigate the effects of the intervention program on metabolic syndrome in cardiovascular patients with hypertension. Before the ANCOVA, its primary and essential assumptions were examined. According to the Shapiro-Willk test results, the distribution of group scores in metabolic syndrome was normal before and after the intervention. The results of Levene's test also confirmed the equality of error variances in the groups (Table 3). The same assumptions were also made about the regression line slope and the equality of error variances in the groups.

Table 1. Summary of the mindfulness-based stress reduction sessions

\begin{tabular}{|c|c|}
\hline Sessions & Content \\
\hline First & $\begin{array}{l}\text { Introducing cardiovascular disease and risk factors. Being familiar with the effect of stress on cardiovascular diseases, } \\
\text { blood pressure, blood sugar, and blood lipids. Teaching meditation and body examination. }\end{array}$ \\
\hline Second & $\begin{array}{c}\text { Continuing the exploration of physical feelings. Learning meditation through awareness of breathing. Practicing and } \\
\text { meditating as homework. }\end{array}$ \\
\hline Third & $\begin{array}{l}\text { Teaching soft mental yoga moves to lighten the global symptoms of stress and become aware of delicate body } \\
\text { movements. Practicing pregnancy exercises, including checking physical feelings, and soft yoga. }\end{array}$ \\
\hline Forth & $\begin{array}{c}\text { Teaching and practicing meditation emphasizing the perception of physical feelings. Determining home practice, } \\
\text { including soft yoga, meditation for a long time, awareness of stress knowledge. }\end{array}$ \\
\hline Fifth & $\begin{array}{c}\text { Practicing the sitting meditation focusing on stress and ways of coping with it in certain situations. Determining home } \\
\text { practice to check physical feelings. Performing yoga and Meditation. }\end{array}$ \\
\hline Sixth & Performing physical meditation. Checking physical feelings. Performing yoga and meditation. \\
\hline Seventh & $\begin{array}{l}\text { Talking. Performing more physical exercises. Applying mindfulness-based stress reduction in everyday life. Determining } \\
\text { home practices, including physical feeling check, yoga, and meditation. }\end{array}$ \\
\hline Eighth & $\begin{array}{l}\text { Overviewing the past sessions. Continuing the practice. Meditating and practicing choiceless awareness. Emphasizing } \\
\text { continuing the practices after the sessions. Asking for feedback from participants about mindfulness and planned training. }\end{array}$ \\
\hline
\end{tabular}


Table 2. Descriptive data of dependent variables in experimental and control groups in pre-test and post-test $(\mathrm{n}=50)$

\begin{tabular}{|c|c|c|c|c|c|c|}
\hline Dependent variables & Group & Phase & Mean & SD & Min. & Max. \\
\hline \multirow{4}{*}{ Systolic blood pressure } & \multirow{2}{*}{ Experimental } & Pre-test & 133.58 & 9.55 & 124 & 144 \\
\hline & & Post-test & 126.16 & 5.63 & 121 & 132 \\
\hline & \multirow{2}{*}{ Control } & Pre-test & 135.54 & 8.77 & 126 & 144 \\
\hline & & Post-test & 134.53 & 8.26 & 126 & 143 \\
\hline \multirow{4}{*}{ Diastolic blood pressure } & \multirow{2}{*}{ Experimental } & Pre-test & 87.98 & 8.71 & 80 & 94 \\
\hline & & Post-test & 79.03 & 4.44 & 75 & 84 \\
\hline & \multirow{2}{*}{ Control } & Pre-test & 88.93 & 7.48 & 81 & 95 \\
\hline & & Post-test & 88.69 & 7.84 & 80 & 94 \\
\hline \multirow{4}{*}{ Fasting blood sugar } & \multirow{2}{*}{ Experimental } & Pre-test & 121.15 & 23.88 & 78 & 165 \\
\hline & & Post-test & 106.54 & 22.46 & 79 & 160 \\
\hline & \multirow{2}{*}{ Control } & Pre-test & 125.14 & 28.55 & 80 & 163 \\
\hline & & Post-test & 123.83 & 26.56 & 80 & 160 \\
\hline \multirow{4}{*}{ Triglycerides } & \multirow{2}{*}{ Experimental } & Pre-test & 175.34 & 61.27 & 102 & 230 \\
\hline & & Post-test & 141.19 & 30.81 & 103 & 181 \\
\hline & \multirow{2}{*}{ Control } & Pre-test & 181.11 & 62.76 & 104 & 219 \\
\hline & & Post-test & 178.07 & 58.21 & 105 & 231 \\
\hline \multirow{4}{*}{ High-density lipoprotein } & \multirow{2}{*}{ Experimental } & Pre-test & 47.10 & 13.63 & 35 & 64 \\
\hline & & Post-test & 52.97 & 12.14 & 35 & 71 \\
\hline & \multirow{2}{*}{ Control } & Pre-test & 45.70 & 12.65 & 36 & 62 \\
\hline & & Post-test & 47.07 & 10.21 & 39 & 65 \\
\hline \multirow{4}{*}{ Low-density lipoprotein } & \multirow{2}{*}{ Experimental } & Pre-test & 117.10 & 35.63 & 63 & 142 \\
\hline & & Post-test & 101.92 & 25.14 & 59 & 123 \\
\hline & \multirow{2}{*}{ Control } & Pre-test & 115.70 & 32.65 & 70 & 140 \\
\hline & & Post-test & 112.14 & 27.59 & 71 & 136 \\
\hline
\end{tabular}

Table 3. Results of Levene's test

\begin{tabular}{|c|c|c|c|c|}
\hline Variables & $\mathbf{F}$ & df1 & df2 & $\mathbf{P}$ \\
\hline Systolic blood pressure & 1.95 & 2 & 54 & 0.15 \\
\hline Diastolic blood pressure & 1.41 & 2 & 54 & 0.25 \\
\hline Fasting blood sugar & 2.07 & 2 & 54 & 0.13 \\
\hline Triglycerides & 1.97 & 2 & 54 & 0.15 \\
\hline High-density lipoprotein & 3.03 & 2 & 54 & 0.06 \\
\hline Low-density lipoprotein & 2.80 & 2 & 54 & 0.09 \\
\hline
\end{tabular}

df: Degrees of freedom

Table 4 presents the results of multivariate analysis of covariance. Accordingly, all four relevant multivariate statistics (i.e., Pillai's trace, Wilk's lambda effect, Hotelling's trace, and Roy's largest root) were significant for the components of metabolic syndrome. There was a significant difference between the experimental and control groups regarding at least one of the components $(\mathrm{P}<0.01)$. The amount of this effect was equal to 0.23 and the power of test was equal to 0.93 .
Subsequently, the effect of the independent variable on each component was separately evaluated using the one-way ANCOVA.

The result of the univariate test was significant for all the dependent variables $(\mathrm{P}<0.05)$. Regarding this, it was concluded that the independent variable separately affects each of the dependent variables. This finding demonstrated that there was a significant difference between the MBSR group and the control group (Table 5).

Table 4. Results of multivariate analysis of covariance

\begin{tabular}{lccccccc}
\hline Tests & Value & df & Error df & F & P & Effect size & Statistical power \\
\hline Pillai's trace & 0.47 & 12 & 88 & 2.26 & 0.010 & 0.23 \\
Wilk's lambda & 0.53 & 12 & 86 & 2.65 & 0.004 & 0.27 \\
Hotelling's trace & 0.86 & 12 & 84 & 3.04 & 0.001 & 0.93 \\
Roy's largest root & 0.85 & 6 & 44 & 6.29 & 0.001 & 0.96 \\
\hline
\end{tabular}

df: Degrees of freedom

Table 5. Results of one-way analysis of covariance

\begin{tabular}{lcccc}
\hline Variables & SS & df & MS & F \\
\hline Systolic blood pressure & 26.36 & 2 & 13.18 & 3.22 \\
Diastolic blood pressure & 15.20 & 2 & 7.60 & 3.12 \\
Fasting blood sugar & 258.09 & 2 & 129.04 & 4.32 \\
Triglycerides & 701.62 & 2 & 350.81 & 0.05 \\
High-density lipoprotein & 49.00 & 2 & 24.50 & 0.02 \\
Low-density lipoprotein & 228.15 & 2 & 114.07 & 3.81 \\
\hline
\end{tabular}

SS: Sum of squares; df: Degrees of freedom; MS: Mean square; F: F-distribution 


\section{Discussion}

The present study aimed to investigate the effectiveness of MBSR on the metabolic syndrome components among cardiovascular patients with hypertension. The findings demonstrated that the MBSR therapy was effective on each component of the metabolic syndrome among cardiovascular patients with hypertension. This finding is consistent with the results of studies performed by Márquez et al. [3], Guyot et al. [4], Geiger et al. [7], and Kharatzadeh et al. [13].

Stress is one of the factors that alone or in combination with other factors play a major role in high blood pressure. During stressful and threatening situations, the arteries of the visceral organs constrict, during which, the pulse beats rapidly and blood pressure rises [26]. There are various reasons according to which MBSR interventions can beneficially affect the biomarkers of metabolic syndrome. First, from a cerebral point of view, mindfulness presents two ways for stress resilience that are increasing the activity and functional connectivity in the stress-regulating parts of the prefrontal cortex and reducing activity and functional connectivity in parts that control the stress alarm system of the brain. It is expected that resilience modulates the responses of the peripheral sympathetic nervous system and hypothalamicpituitary-adrenal axis to external stressors [27]. Second, mindfulness interventions affect health behaviors related to stress. Moreover, they probably influence biomarkers [28]. Third, this intervention affects the regulation of emotion, self-awareness, attention control, and concentration through psychological mechanisms [29].

Hypertension is by far the most prevalent individual component among those of the metabolic syndrome and is found in 50\%-76\% of patients. Both obesity and insulin resistance are known to be associated with increased blood pressure; nevertheless, the etiology of hypertension is likely multifactorial. The compensatory hyperinsulinemia may induce hypertension by a number of mechanisms, including chronic stimulation of the sympathetic and vascular tone $[30,31]$.

A raft of clinical and experimental evidence emphasizes the role of stress in obesity and metabolic syndrome, with the resultant degree and pattern of sympathetic activation influencing the development of obesity-related illnesses, including hypertension; insulin resistance; and renal, cardiac, and vascular impairment [32]. Mindfulness helps people deal better with stress, pain, and illness. This method improves the state of mindfulness in individuals and ameliorates patients' health behaviors by reducing rumination and emotional avoidance and increasing self-regulatory behaviors [9]. Moreover, mindfulness training makes patients less judgmental regarding issues and events, be more patient, and consider the upcoming events and issues as if they were facing them for the first time. In other words, the patients try to perceive the events in a new way each time rather than ignoring them or reacting with excessive emotions that are based on past experiences. Judgment causes stress in hypertension patients in many situations. Consequently, the employment of ineffective coping strategies increases the experience of negative feelings and stress. This vicious cycle can lead to an increase in diseases, disorders, and symptoms.

Considering that the treatment of the metabolic syndrome and prevention of its symptoms are highly dependent on how the individual performs self-care behaviors, improvement in the patient's level of mindfulness in this regard will lead to a rise in controlling the symptoms and adhering to self-care behaviors. Consequently, the symptoms of metabolic syndrome in patients with hypertension will improve using this type of intervention. A noteworthy point in the results of this research was the significant levels of difference between the experimental and control groups, which was on the borderline regarding many indicators. This statistical finding clinically indicated that since patients in both groups were being treated by a specialist physician and were taking medications, improvement in symptoms was evident in both groups.

Regarding that this research was conducted on patients with hypertension, who underwent treatment, the achieved results should be cautiously generalized to other individuals and groups of society. Moreover, as the participants of all groups voluntarily participated in learning sessions, the motivating factor should be considered in the improvement of individuals. Due to the limitations of patients, accomplishing the follow-up phase was not feasible in this study.

\section{Conclusions}

Therefore, it is suggested that the follow-up stage be performed in future studies to investigate the effect of treatment on patients' recovery process. It is also recommended to conduct the study using gender-disaggregated data.

\section{Ethical considerations}

The study was approved by the Ethical Committee of Islamic Azad University, Karaj Branch, Karaj, Iran (IR.IAU.K.REC. 
1398.077).

\section{Acknowledgments}

This article was extracted from a part of a $\mathrm{PhD}$ dissertation of Kourosh Shahbazi submitted to the Department of Psychology, Karaj Branch, Islamic Azad University. The authors would like to thank all the individuals who participated in the study and the staff of the Shahrekord Cohort Study.

\section{Funding/Support}

This research received no specific grant from any funding agency in the public, commercial, or not-for-profit sectors.

\section{Conflicts of Interest}

The authors declare that there is no conflict of interest.

\section{References}

1.Mancia G, Fagard R, Narkiewicz K, Redon J, Zanchetti A Buhm M, et al. ESH / ESC clinical practice guide for the management of arterial hypertension (2013). Hypertension and Vascular Risk. 2013; 30:4-91. [DOI:10.1016/S18891837(13)70027-8]

2. Reid RD, Morrin LI, Beaton LJ, Papadakis S, Kocourek J McDonnell L, et al. Randomized trial of an internet-based computer-tailored expert system for physical activity in patients with heart disease. European Journal of Preventive Cardiology. 2012; 19(6):1357-64. [DOI:10.1177/1741826711422988] [PMID]

3.Mбrquez PH, Feliu-Soler A, Soln̄-Villa MJ, Matas-Pericas L, Filella-Agullo D, Ruiz-Herrerias $M$, et al. Benefits of mindfulness meditation in reducing blood pressure and stress in patients with arterial hypertension. Journal of Human Hypertension. 2019; 33(3):237-47. [DOI:10.1038/s41371018-0130-6] [PMID]

4. Guyot E, Baudry J, Hercberg S, Galan P, Kesse-Guyot E, Рйneau $\mathrm{S}$. Mindfulness is associated with the metabolic syndrome among individuals with a depressive symptomatology. Nutrients. 2018; 10(2):232. [DOI:10.3390/nu10020232] [PMID] [PMCID]

5.Dunkley AJ, Charles K, Gray LJ, Camosso- Stefinovic J, Davies MJ, Khunti K. Effectiveness of interventions for reducing diabetes and cardiovascular disease risk in people with metabolic syndrome: systematic review and mixed treatment comparison meta- analysis. Diabetes, Obesity and Metabolism. 2012; 14(7):616-25. [DOI:10.1111/j.14631326.2012.01571.x] [PMID]

6.McMahon SR, Ades PA, Thompson PD. The role of cardiac rehabilitation in patients with heart disease. Trends in Cardiovascular Medicine. 2017: 27(6):420-5. [DOI:10.1016/j.tcm.2017.02.005] [PMID] [PMCID]

7. Geiger PJ, Boggero IA, Brake CA, Caldera CA, Combs HL, Peters JR, et al. Mindfulness-based interventions for older adults: a review of the effects on physical and emotional well-being. Mindfulness. 2016; 7(2):296-307. [DOI:10.1007/s12671-015-0444-1] [PMID] [PMCID]

8. Johannsen $M$, $\mathrm{O}^{\prime}$ Connor $M$, $\mathrm{O}^{\prime}$ Toole $M S$, Jensen $A B$, Zachariae R. Mindfulness-based cognitive therapy and persistent pain in women treated for primary breast cancer: exploring possible statistical mediators: results from a randomized controlled trial. The Clinical Journal of Pain. 2018; 34(1):59-67. [DOI:10.1097/AJP.0000000000000510] [PMID]

9. Anheyer D, Leach MJ, Klose P, Dobos G, Cramer H. Mindfulnessbased stress reduction for treating chronic headache: a systematic review and meta-analysis. Cephalalgia. 2019; 39(4):544-55. [DOI:10.1177/0333102418781795] [PMID]

10. Giannandrea A, Simione L, Pescatori B, Ferrell K, Belardinelli MO, Hickman SD, et al. Effects of the mindfulness-based stress reduction program on mind wandering and dispositional mindfulness facets. Mindfulness. 2019; 10(1):185-95. [DOI:10.1007/s12671 018-1070-5]

11. Cherkin DC, Sherman KJ, Balderson BH, Cook AJ, Anderson $\mathrm{ML}$, Hawkes RJ, et al. Effect of mindfulness-based stress reduction vs cognitive behavioral therapy or usual care on back pain and functional limitations in adults with chronic low back pain: a randomized clinical trial. JAMA. 2016;
315(12):1240-9. [DOI:10.1001/jama.2016.2323] [PMID]

12. Pascoe MC, Thompson DR, Ski CF. Yoga, mindfulnessbased stress reduction and stress-related physiological measures: a meta-analysis. Psychoneuroendocrinology. 2017; 86:152-68. [DOI:10.1016/j.psyneuen.2017.08.008] [PMID]

13. Kharatzadeh $H$, Davazdah Emamy $M H$, Bakhtiary $M$ Kachuei A, Mahaki B. Effectiveness of mindfulness-based stress reduction on glycemic control, stress, anxiety and depression in patients with type 2 diabetes mellitus. Studies in Medical Sciences. 2017; 28(3):206-14.

14. Salim Bahrami $\mathrm{SH}$, Jahan $\mathrm{F}$, Asadzadeh Dehraei $\mathrm{H}$ Sotoodeh Asl N. Effectiveness of mindfulness training on anxiety reduction as well as improvement of life quality and perceived academic control of students. Avicenna Journal of Neuro Psycho Physiology. 2020; 7(2):69-76. [DOI:10.32592/ajnpp.2020.7.2.100]

15. Jafari A, Shahabi S R. Effectiveness of mindfulness-based stress reduction on state/trait anxiety and quality of life in women with obesity. Feyz. 2017; 21(1):83-93.

16. Masumian S, Shairi MR, Hashemi M. The effect of mindfulness-based stress reduction on quality of life of the patients with chronic low back pain. Journal of Anesthesia and Pain. 2013; 4(3):25-37.

17. Shabani M, Ghari Saadati L. Comparison of the effectiveness of mindfulness-based cognitive therapy and quality of life therapy on perfectionism and rumination in patients with migraine. Avicenna Journal of Neuro Psycho Physiology. 2019; 6(1):1-10. [DOI:10.32598/ajnpp.4.3.295]

18. Tang HY, Harms V, Vezeau T. An audio relaxation tool for blood pressure reduction in older adults. Geriatric nursing 2008; 29(6):392-401. [DOI:10.1016/j.gerinurse.2008.02.003] [PMID]

19. Zare H, Zare M, Khalegi Delavar F, Amirabadi F, Shahriari $H$. Mindfulness and diabetes: evaluation of effectiveness of Mindfulness Based Stress Reductionon glycemic control in diabetes. Razi Journal of Medical Sciences. 2013; 20(108):40-52.

20. Mohammadi Shirmahaleh F, Jomehri F, Kraskian A, Malihi Alzakerini S. Effectiveness of mindfulness on reducing anxiety and blood sugar of patients with diabetes and behavioral inhibition system (BIS) personality type. Journal of Applied Psychology. 2016; 10(38):139-56.

21. Daubenmier J, Moran PJ, Kristeller J, Acree M, Bacchetti P Kemeny ME, et al. Effects of a mindfulness- based weight loss intervention in adults with obesity: a randomized clinical trial. Obesity. 2016; 24(4):794-804. [DOI:10.1002/oby.21396] [PMID] [PMCID]

22. Guyot E, Baudry J, Hercberg S, Galan P, Kesse-Guyot E, Pñneau S. Mindfulness is associated with the metabolic syndrome among individuals with a depressive symptomatology. Nutrients. 2018; 10(2):232. [DOI: 10.3390/nu10020232] [PMID] [PMCID]

23. Monin JK, Sperduto CM, Manigault AW, Dutton A, Clark MS, Jastreboff AM. Mindfulnes-based stress reduction for older couples with metabolic syndrome: a pilot randomized controlled trial. Mindfulness. 2020; 11(4):917-27. [DOI:10.1007/s12671-019-01301-9] [PMID] [PMCID]

24. Aronow WS. Blood pressure goals and targets in the elderly. Current Treatment Options in Cardiovascular Medicine. 2015; 17(7):394. [DOI:10.1007/s11936-015-0394-x] [PMID]

25. Kabat-Zinn J. Full catastrophe living, revised edition: how to cope with stress, pain and illness using mindfulness meditation. Paris, France: Hachette Livre; 2013.

26. Heidaran F, Sajjadian I, Fathi M. Effectiveness of hypnotherapy on the perceived stress and blood pressure in patients with primary hypertension. Medical Journal of Mashhad University of Medical Sciences, 2017; 60(5):669. 80. [DOI:10.22038/MJMS.2017.10451]

27. Creswell JD, Lindsay EK. How does mindfulness training affect health? A mindfulness stress buffering account Current Directions in Psychological Science. 2014; 23(6):401-7. [DOI:10.1177/0963721414547415]

28. Li W, Howard MO, Garland EL, McGovern P, Lazar M. Mindfulness treatment for substance misuse: A systematic review and meta-analysis. Journal of Substance Abuse Treatment. 2017; 75:62-96. [DOI:10.1016/j.jsat.2017.01.008] [PMID] 
29. Creswell JD, Lindsay EK, Villalba DK, Chin B. Mindfulness training and physical health: mechanisms and outcomes. Psychosomatic Medicine. 2019; 81(3):224-32. [DOI: 10.1097/PSY.0000000000000675] [PMID] [PMCID]

30. Lau DC, Yan H, Dhillon B. Metabolic syndrome: a marker of patients at high cardiovascular risk. The Canadian Journal of Cardiology. 2006; 22(Suppl B):85B-90B.

[DOI:10.1016/s0828-282x(06)70992-8] [PMID] [PMCID]
31. Samson SL, Garber AJ. Metabolic syndrome. Endocrinology and Metabolism Clinics of North America. 2014; 43(1):1-23. [DOI:10.1016/j.ecl.2013.09.009] [PMID]

32. Lambert EA, Lambert GW. Stress and its role in sympathetic nervous system activation in hypertension and the metabolic syndrome. Current Hypertension Reports. 2011; 13(3):244 8. [DOI:10.1007/s11906-011-0186-y] [PMID] 